\title{
A real-time reverse transcriptase polymerase chain reaction for detection and quantification of Vesiculovirus
}

\author{
Aline Lavado Tolardo ${ }^{1 /}{ }^{+}$, William Marciel de Souza ${ }^{1}$, Marilia Farignoli Romeiro', \\ Luiz Carlos Vieira', Luciano Kleber de Souza Luna', Dyana Alves Henriques², Jansen de Araujo², \\ Carlos Eduardo Hassegawa Siqueira ${ }^{3}$, Tatiana Elias Colombo ${ }^{4}$, Victor Hugo Aquino ${ }^{5}$, \\ Benedito Antonio Lopes da Fonseca ${ }^{1}$, Roberta Vieira de Morais Bronzoni ${ }^{3}$, \\ Maurício Lacerda Nogueiraa ${ }^{4}$, Edison Luiz Durigon' ${ }^{2}$, Luiz Tadeu Moraes Figueiredo ${ }^{1}$
}

\footnotetext{
${ }^{1}$ Universidade de São Paulo, Faculdade de Medicina de Ribeirão Preto, Centro de Pesquisa em Virologia, Ribeirão Preto, SP, Brasil ${ }^{2}$ Universidade de São Paulo, Instituto de Ciências Biomédicas, Laboratório de Virologia Clínica e Molecular, São Paulo, SP, Brasil ${ }^{3}$ Universidade Federal de Mato Grosso, Instituto de Ciências da Saúde, Centro Universitário de Sinop, Sinop, MT, Brasil ${ }^{4}$ Faculdade de Medicina de São José do Rio Preto, Laboratório de Pesquisa em Virologia, São José do Rio Preto, SP, Brasil ${ }^{5}$ Universidade de São Paulo, Faculdade de Ciências Farmacêuticas de Ribeirão Preto, Departamento de Análises Clínicas, Toxicológicas e Bromatológicas, Laboratório de Virologia, Ribeirão Preto, SP, Brasil
}

Vesiculoviruses (VSV) are zoonotic viruses that cause vesicular stomatitis disease in cattle, horses and pigs, as well as sporadic human cases of acute febrile illness. Therefore, diagnosis of VSV infections by reliable laboratory techniques is important to allow a proper case management and implementation of strategies for the containment of virus spread. We show here a sensitive and reproducible real-time reverse transcriptase polymerase chain reaction (RT-PCR) for detection and quantification of VSV. The assay was evaluated with arthropods and serum samples obtained from horses, cattle and patients with acute febrile disease. The real-time RT-PCR amplified the Piry, Carajas, Alagoas and Indiana Vesiculovirus at a melting temperature $81.02 \pm 0.8^{\circ} \mathrm{C}$, and the sensitivity of assay was estimated in 10 RNA copies/mL to the Piry Vesiculovirus. The viral genome has been detected in samples of horses and cattle, but not detected in human sera or arthropods. Thus, this assay allows a preliminary differential diagnosis of VSV infections.

Key words: Vesiculovirus - quantitative real-time RT-PCR - diagnosis of vesicular stomatitis - zoonotic virus

Vesiculovirus (VSV) genus belongs to Rhabdoviridae family and shares a common elongated bullet-like shape. VSV are enveloped with helical nucleocapsids containing a single strand, negative-sense RNA. VSV are enzootic and maintained in nature by not fully understood mechanisms (Lichty et al. 2004). Experimental studies indicate that mosquitoes and sand flies can transmit VSV among reservoir animals and eventually, to humans (Mead et al. 2000). Alternatively, VSV can be transmitted by infected animals through direct contact or fomites (Smith et al. 2009).

Currently, nine species of VSV are recognised by the International Committee on Taxonomy of Viruses (ICTV). From those, vesicular stomatitis Alagoas virus (VSAV), vesicular stomatitis New Jersey virus (VSNJV) and vesicular stomatitis Indiana virus (VSINV) are endemic in the Americas. The infection by these viruses produces the vesicular stomatitis, a disease of cattle, horses, sheep and pigs, which is characterised by fever, gen-

doi: 10.1590/0074-02760150456

Financial support: FAPESP (grant $\mathrm{n}^{\circ} 13 / 14929-1$ and scholarships 13/02256-2, 12/02836-6, 12/24150-9, 14/15079-4).

LTMF is recipient of a CNPq 1B senior fellowship (301677/2013-1).

+ Corresponding author: alinetolardo@hotmail.com

Received 17 December 2015

Accepted 6 May 2016 eration of vesicles in oral mucosa, skin, teat and coronary band. Vesicular stomatitis reduces the productivity of the animals, and it is economically important, thus requiring animal control by quarantines and trade barriers (Rodriguez 2002, Figueiredo 2011, Cargnelutti et al. 2014).

From June-August 2013, cases of vesicular stomatitis disease affecting horses and cattle were reported to the Veterinary Hospital of the Federal University of Campina Grande, Paraiba state, Brazil. These outbreaks occurred in the towns of Paulista, São Bento, Patos, in Paraiba state, and Umarizal, Rio Grande do Norte state. To confirm the laboratory diagnostic, the samples were subjected to reverse transcriptase polymerase chain reaction (RT-PCR) able to differentiate between the VSAV and VSINV (Pauszek et al. 2011). Thus, the virus found in the samples was the VSAV, which also was subsequently sequenced and deposited in GenBank (Cargnelutti et al. 2014).

The Chandipura (CHPV) and Isfahan vesiculovirus are arthropod-borne VSV have been associated with important cases of an acute febrile disease in humans (Tesh et al. 1977, Menghani et al. 2012). CHPV has also been reported to cause severe encephalitis in children in Asia (Rajasekharan et al. 2014). In South America, human infections by VSV are rarely reported. However, serological studies have reported a high prevalence (417.7\%) of specific Piry vesiculovirus (PIRYV) neutralising antibodies in populations from different regions of Brazil (Pinheiro et al. 1974, Figueiredo et al. 1985, Tavares-Neto et al. 1990). In addition, human disease was 
reported in five cases, all related to laboratory accidents, with typical acute infectious viral disease (Pinheiro et al. 1974, Figueiredo et al. 1985, Souza et al., in press). In the 1960', PIRYV, Cocal and Maraba virus were isolated in Brazil from opossum (Philander opossum), mites (Gigantolaelaps $s p$ ) and sand flies (Lutzomyia $s p$ ), respectively. However, the importance of these viruses in human public health is practically unknown (Travassos da Rosa et al. 1984, Souza et al., in press).

The diagnosis of VSV infection has been done mostly based on serologic tests (ELISA - Enzyme-linked immunosorbent assay), virus neutralisation, and/or isolation (Afshar et al. 1993, Figueiredo 2011, Menghani et al. 2012). Despite being easily propagated in cell culture, VSV diagnostic techniques by neutralisation and virus isolation are timeconsuming and labor intensive. In the last decades, the detection of the viral genome by molecular techniques has been successfully used (Bonutti \& Figueiredo 2005, Hole et al. 2006, Wilson et al. 2009, Cargnelutti et al. 2014).

The development of real time RT-PCR allows the quantification of the final amplified product, allowing extrapolating the initial amount of target DNA in the sample. In contrast, most conventional PCR assays are only qualitative. Due to the exponential amplification of the DNA, any variation in the conventional technique during the amplification can lead to large variations in the amount of the final product amplified. The real-time RT-PCR allowed an increase in automatisation of reactions, reducing the risk of human error (Mackay 2004). Using this molecular approach, we show here an easy, sensitive, and reproducible real-time RT-PCR for detection and quantification of VSV.

\section{MATERIALS AND METHODS}

Primers design - The sequences for the glycoprotein complete gene of vesiculoviruses were retrieved from GenBank of National Center for Biotechnology Information (NCBI) database. These sequences were from PIRYV (D26175), CHPV (NC_020805; GU212858), Perinet virus (NC_025394), VSIV (AF473864; EU849003; AM690337; AF473865; AF473866), VSAV (NC_025353), VSNJV (KC905171; KP202364; KM012169; JX121111; JX121112; JX121110; NC 024473; JX121104) and Carajas virus (KM205015). The sequences were aligned using
MAFFT v7.158b (Katoh \& Standley 2013) and conserved regions in the glycoprotein sequences were utilised to design primers using the Geneious v.8.0.1 program. However, the primers set was design to conserved region, the primers is predominantly based on PIRYV. The primers that amplify 222 base pairs (bp) are Piry-Forward: 5'-CAGGTGGTATGGRCCSAAATA-3' (Position 3395 to 3415) and Piry-Reverse: 5'-ATCCAGTGACCTCTATAATCATC-3', (Position 3616 to 3594), both primers based on coding sequence of PIRYV (GenBank No. KU178986). Primer sequences were compared to other nucleotide sequences deposited in the collection database and cross-reactivation with common human pathogens was not observed. Subsequently these sets of primers were synthesised (Sigma Aldrich, São Paulo, Brazil).

Viruses - The VSV used for this study were PIRYV, Carajas, VSAV and VSINV (Table I). The viruses were propagated in C6/36 Aedes albopictus cells, and maintained for 36 hours at $28^{\circ} \mathrm{C}$ with Leibovitz's-15 (L-15) medium supplemented with $10 \%$ heat-inactivated fetal bovine serum (FBS), $50 \mathrm{mg} / \mathrm{mL}$ of gentamicin and $2 \mathrm{mg} /$ $\mathrm{mL}$ of amphotericin B (Vitrocell, Campinas, SP, Brazil).

Viral RNA extraction and cDNA synthesis - The RNA of viruses and samples were extracted using the QIAamp Viral RNA Mini Kit (Qiagen, Germany) according to the manufacturer's protocol. The RNA was recovered in 60 $\mu \mathrm{L}$ of RNase-free water and stored at $-70^{\circ} \mathrm{C}$.

For the reaction of cDNA synthesis, extracted RNA was reverse transcribed with $200 \mathrm{U}$ M-MLV (Invitrogen, Waltham, MA, USA), $10 \mu \mathrm{M}$ random primers, 2.5 nM dNTPs, 0.1 M DTT, 20U RNAse-OUT (Invitrogen, Waltham, MA, USA) and RNase-free water. The reaction was incubated at $37^{\circ} \mathrm{C}$ for $1 \mathrm{~h}$, followed by enzyme inactivation at $70^{\circ} \mathrm{C}$ for $15 \mathrm{~min}$. The cDNA samples were stored at $-20^{\circ} \mathrm{C}$ until processed.

Real-time PCR for Vesiculovirus - The real-time PCR for VSV was performed in a StepOnePlus realtime PCR System (Applied Biosystems, Foster City, CA, USA). The reaction was standardised using the KAPA SYBR FAST Universal 2X qPCR Master Mix (Kapa Biosystems, Wilmington, MA, USA). The SYBR FAST Universal 2X qPCR Master Mix (Kapa Biosystems, Wilmington, MA, USA) was used in a reaction mixture

TABLE I

Viruses used to development of real-time reverse transcriptase polymerase chain reaction for Vesiculovirus

\begin{tabular}{lcccc}
\hline Genus & Virus & Strain & $\mathrm{T}_{\mathrm{M}}$ peak $\left({ }^{\circ} \mathrm{C}\right)$ & Quantify $(\mathrm{RNA}$ copies $/ \mathrm{mL})$ \\
\hline Vesiculovirus & Piry & Be An 41191 & $81,5 \pm 0,1$ & $2,3 \times 10^{6}$ \\
Vesiculovirus & Carajas & Be An 411459 & $81,3 \pm 0,0$ & $1,4 \times 10^{6}$ \\
Vesiculovirus & Alagoas & Bn $/ 64$ & $81,8 \pm 0,02$ & $1,2 \times 10^{6}$ \\
Vesiculovirus & Indiana & BN/79 & $81,4 \pm 0,04$ & $1,8 \times 10^{5}$ \\
Alphavirus & Mayaro & BeAr 20290 & $72,4 \pm 0,08$ & na \\
Flavivirus & Rocio & SPH 34675 & $70,3 \pm 0,10$ & na \\
Orthobunyavirus & Oropouche & BeAn19991 & $75,3 \pm 0,09$ & na \\
\hline
\end{tabular}

na: not amplified; $\mathrm{T}_{\mathrm{M}}$ : melting temperature. 
including $2 \mu \mathrm{L}$ of cDNA template: $2 \mu \mathrm{L}$ of each primer (Piry-Forward and Piry-Reverse at $2.5 \mathrm{mM}$ per $\mu \mathrm{L}$ of all studied VSV; $0,4 \mu \mathrm{L}$ of ROX buffer (2X); $10 \mu \mathrm{L}$ of SYBR buffer (2X); and 3.6 $\mu \mathrm{L}$ of DEPC (Diethylpyrocarbonate) water, for a volume reaction of $20 \mu \mathrm{L}$. Different temperature cycles were also tested, and an optimal reaction was obtained with $95^{\circ} \mathrm{C}$ for 10 min (to activate the Taq polymerase and separate double-stranded DNAs); and 45 cycles at $95^{\circ} \mathrm{C}$ for $15 \mathrm{~s}$ for denaturation; $60^{\circ} \mathrm{C}$ for 1 min for primer annealing.

Plasmid cloning - The amplicon of 222 nucleotides containing part of glycoprotein gene of PIRYV, obtained by RT-PCR with the selected primers, was cloned into the pET28a vector and introduced into Escherichia coli DH5 $\alpha$ One Shot (Invitrogen, Waltham, MA, USA) following the manufacturer's protocol. After transformation of competent cells with the insert, the plasmid DNA was isolated using the QIAprep Spin Miniprep Kit (Qiagen, Hilden, Germany).

In vitro transcription - A PCR was performed to amplify the 222 nucleotides of VSV inserted into the plasmid using Taq DNA polymerase (Invitrogen, Waltham, MA, USA), 5'-end primer containing T7 promoter region (5'-TAATACGACTCACTATAGGG-3') and a T7 terminator region (5'-GCTAGTTATTGCTCAGCGG-3'), as recommended by the manufacturer. The cycling conditions were the following: 3 minutes for initial denaturation at $94^{\circ} \mathrm{C}$, followed by 45 cycles with $45 \mathrm{~s}$ at $94^{\circ} \mathrm{C}$ for denaturation, $30 \mathrm{~s}$ at $58^{\circ} \mathrm{C}$ for annealing and $90 \mathrm{~s}$ at $72^{\circ} \mathrm{C}$ for extension. Finally, it was also used an extension of $5 \mathrm{~min}$ at $72^{\circ} \mathrm{C}$. The amplicon was purified using the QIAquick PCR Purification Kit (Qiagen, Hilden, Germany) and transcribed in vitro using a MEGAscript ${ }^{\circledR}$ T7 Transcription Kit (Invitrogen, Waltham, MA, USA), all following the manufacturer's instructions. The reaction product was treated with $30 \mathrm{U}$ of Turbo DNAse-free (Invitrogen, Waltham, MA, USA), incubated 4 hours at $37^{\circ} \mathrm{C}$ and inactivated at $70^{\circ} \mathrm{C}$ for $15 \mathrm{~min}$. Finally, it was performed the RNA purification using RNeasy kit (Qiagen, Hilden, Germany), the RNA load was determined in a Qubit ${ }^{\circledR} 2.0$ Fluorometer (Invitrogen, Waltham, MA, USA) and the product was stored at $-70^{\circ} \mathrm{C}$.

Standard curve, detection limit and specificity - The standard curve for VSV-RNA quantitation was obtained with serial ten-fold dilutions of the transcribed RNA. The assay was performed in triplicate and the concentration was measured in copies per $\mathrm{mL}$, was converted to copy number using the following formula: RNA copy number (copies/ $\mathrm{mL})=($ RNA concentration $(\mathrm{g} / \mathrm{mL}) /$ number of nucleotides of transcript $\times 340) \times 6.022 \times 10^{23}$. For each new reaction, was obtained a standard curve based on the results obtained from the serial dilutions of the transcribed product.

Samples - Human sera - A total of 410 sera from patients with acute febrile illnesses were tested by the real-time RT-PCR for VSV. Dengue virus was not previously detected by conventional RT-PCR in these samples (Bronzoni et al. 2005). The sera included 88 samples from patients obtained during an outbreak of Dengue virus, 2006-2014, at São José do Rio Preto city (155 sam- ples), Ribeirão Preto city (188 samples), both in São Paulo state, Brazil, and 67 samples from Sinop city, Mato Grosso state, Brazil. This study was approved by the Human Research Ethics Committee, School of Medicine of University of São Paulo, Brazil (Process No. 2013/164.277).

Arthropod pools - Seventy-six lots of arthropods were tested by real-time RT-PCR to detect Vesiculovirus in potential vectors. The samples included: 57 pools of different species of mosquitos, collected in 2007, in different places of Rondônia state, Brazil. Also, were included 19 pools of ticks collected in domestic animals in 2014, in Ribeirão Preto city, São Paulo state (10 pools of Rhipichephalus sp and 9 pools of Amblyomma $s p$ ). The samples of arthropods were disrupted and homogenised with TissueLyser II (Qiagen, Hilden, Germany). The RNA of all samples was extracted using the QIAamp Viral RNA Mini Kit (Qiagen, Hilden, Germany) and cDNAs were obtained as described above.

Cattle and horses - The real-time RT-PCR for VSV was also used to test serum samples from 18 cattle and horses obtained during an outbreak of VSV in towns of northeastern of Brazil (Cargnelutti et al. 2014). These samples were kindly provided by Prof Dr Eduardo Furtado Flores and Dr Juliana Cargnelutti, from the Federal University of Santa Maria, Rio Grande do Sul, Brazil.

\section{RESULTS}

The parameters obtained with decimal dilutions of the in vitro transcribed RNA for the standard curve of the quantitative SYBR Green real-time RTPCR are the following: slope -3.036 , percentage efficiency (EFF) $113.508 \%$; correlation coefficient $\left(R_{2}\right) 0.978$ and Y-inter 39.28. The threshold value of 1.636 for the RNA dilutions was reproducible with a $\mathrm{T}_{\mathrm{M}}$ (melting temperature) peak of $81.06^{\circ} \mathrm{C}$ to $82.1^{\circ} \mathrm{C}$ (Fig. 1 ).

The real-time RT-PCR showed a sensitivity of 10 copies/mL for all the VSV tested (Alagoas, Carajas, PIRYV and VSINV) and specific $\mathrm{T}_{M}$ peaks without the formation of primer-dimer for all of them, as shown in Table I and Fig. 2. Besides, the genomes of Flavivirus (Rocio strain SPH 34675, Cacipacore strain BeAn 327600 and Ilheus virus strain $\mathrm{BeH} 7445$ ) and Orthobunyavirus (Oropouche strain BeAn19991), used as negative controls, were not amplified in the test.

The real-time RT-PCR was able to detect the virus genome in 15 of 17 serum samples from cattle and horses obtained during an outbreak of Alagoas virus. There was no significant difference between VSV loads observed in horses $\left(1.5 \times 10^{1}\right.$ to $2 \times 10^{6}$ RNA copies $\left./ \mathrm{mL}\right)$ and those from bovines ( $1.4 \times 10^{1}$ to $1.2 \times 10^{5} \mathrm{RNA}$ copies $\left./ \mathrm{mL}\right)$, as shown in Table II. Unfortunately, the VSV genome was not detected in human sera, as well as in the arthropods analysed in the study.

\section{DISCUSSION}

VSV detection by laboratory tests such as virus isolation (gold standard), serologic tests, or neutralisation assays is time-consuming. Additionally, the available conventional PCR assays usually detect few species VSV and an extra electrophoresis step is required to visualise 
A

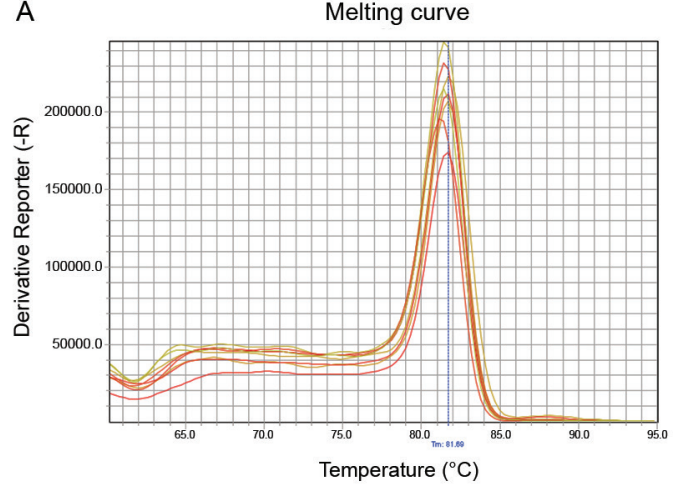

B

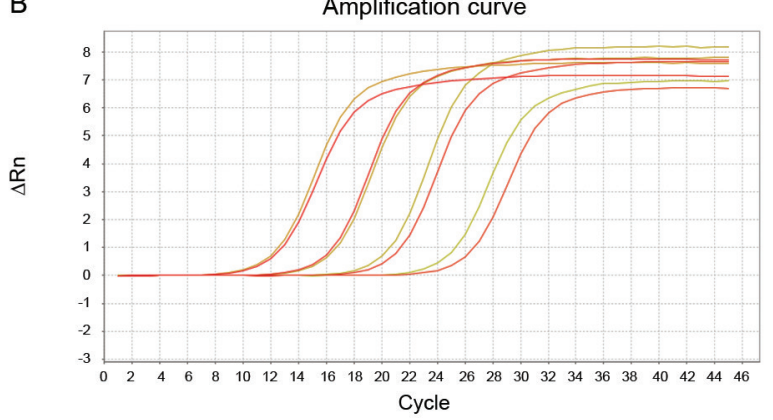

Fig. 1: standard line of real-time reverse transcriptase polymerase chain reaction (RT-PCR) with transcribed RNA of Vesiculovirus. (A) Standard line with serial decimal dilutions of transcribed RNA. (B) Amplification curve obtained from of serial decimal dilutions of transcribed RNA. (C) Melting peaks of real-time RT-PCR of serial decimal dilutions of the transcribed RNA.

the amplificons (Rodriguez et al. 1993, Fernández et al. 2008). Therefore, we decided to develop a real-time RTPCR assay to detect a broad range of VSV species that could also be used for epidemiological surveillance.

Molecular techniques have been previously used for VSV diagnosis, as well as probes has been developed for differentiation of VSNJV and VSINV (Hole et al. 2006) or for detection and quantification of CHPV (Kumar et al. 2008). To the best of our knowledge, no real-time RTPCR using SYBR Green methodology has been reported for detection of VSV.

The real-time RT-PCR for VSV was set using the SYBR Green I method and including specially designed primers that anneal in highly conserved region of the glycoprotein of VSV. The primers were able to amplify the genomes of four taxonomically distinct VSV: VSINV (Indiana 1 group), VSAV (Indiana 3 group), Carajas virus (isolated from an insect and taxonomically closer related to VSNJV) and PIRYV (South American zoonotic virus). Therefore, based on the primer design and on our results, it is strongly probable that this SYBR Green I real-time RTPCR can be used to detect, practically, all American VSV.

The lower cost compared to TaqMan technique, coupled with the fact that we developed a generic PCR, led us to the choice of SYBR Green real-time method. Although less specific than TaqMan, SYBR Green allowed a specific generic identification of the VSV, since this
TABLE II

Samples positive found in this study by real-time reverse transcriptase polymerase chain reaction for vesicular stomatitis Alagoas virus

\begin{tabular}{lcc}
\hline Samples $^{1}$ & $\mathrm{~T}_{\mathrm{M}}\left({ }^{\circ} \mathrm{C}\right)$ & Viral load (RNA copies $/ \mathrm{mL})$ \\
\hline 01 Equine & $81,3 \pm 0,00^{*}$ & $1,2 \times 10^{6}$ \\
02 Equine & $81,1 \pm 0,10$ & $1,3 \times 10^{4}$ \\
03 Equine & $81,1 \pm 0,00^{*}$ & $1,9 \times 10^{1}$ \\
04 Equine & $81,2 \pm 0,10$ & $2,6 \times 10^{1}$ \\
05 Equine & $81,4 \pm 0,09$ & $1,3 \times 10^{4}$ \\
06 Equine & $81,02 \pm 0,10$ & $2,3 \times 10^{4}$ \\
07 Equine & $81,1 \pm 0,00^{*}$ & $1,5 \times 10^{1}$ \\
08 Equine & $81,7 \pm 0,08$ & $1,5 \times 10^{1}$ \\
09 Equine & $81,3 \pm 0,07$ & $5,5 \times 10^{2}$ \\
10 Equine & $81,1 \pm 0,20$ & $5,7 \times 10^{2}$ \\
01 Bovine & $81,2 \pm 0,10$ & $1,2 \times 10^{5}$ \\
02 Bovine & $81,4 \pm 0,09$ & $2,1 \times 10^{2}$ \\
03 Bovine & $81,7 \pm 0,00^{*}$ & $8,3 \times 10^{3}$ \\
04 Bovine & $81,6 \pm 0,20$ & $1,4 \times 10^{1}$ \\
05 Bovine & $81,5 \pm 0,04$ & $9,1 \times 10^{3}$
\end{tabular}

$\mathrm{T}_{\mathrm{M}}$ : melting temperature; *Standard deviation less than 0.001 ; ${ }^{1}$ Cargnelutti et al. (2014).

technique has amplify the four virus specifically and efficiently and did not amplify other viruses tested, for example, Orthobunyavirus, Alphavirus and Flavivirus. The advantages this assay are: (i) low cost, (ii) capable to detect and quantify VSVs, (iii) binding of SYBR Green to nucleic acid is not virus specific and the fluorescent signal produced, when in complex with DNA, is precise and directly proportional to the length and the amount of DNA copies synthesised (Papin et al. 2004).

The real-time RT-PCR was highly sensitive with a limit of detection of 10 copies of RNA per mL. Also, this assay has been showed that is genus-specific because primer dimers or unspecific amplification were not observed and crossamplification with genomes of other arbovirus such as Orthobunyavirus, Alphavirus, and Flavivirus, did not occur. We report a percentage efficiency (EFF) was higher than $100 \%$. This value is within the accepted range $(90-120 \%)$ recommended by the manufacturer. Also, the efficiency of the assays is supported by appropriate R2 and slope values. Also, the amplicons were visualised by electrophoresis (Data not shown).

The test was able to detect VSAV with variable titers in 15 of 18 sera from cattle and horses that were obtained during an outbreak, previously reported in northeastern Brazil (Cargnelutti et al. 2014). On the other hand, we believe that improper storage of samples at $-20^{\circ} \mathrm{C}$ resulted in a decrease in viral loads, including low VSAV titers and non-detection of the genome into three sera samples. The samples were previously sequenced by Cargnelutti et al. (2014). This demonstrates that this assay can be useful for VSV diagnosis of animals, especially since the acute phase of infection by VSV generally have high titers (Schmitt 2002). 
A

Standard line

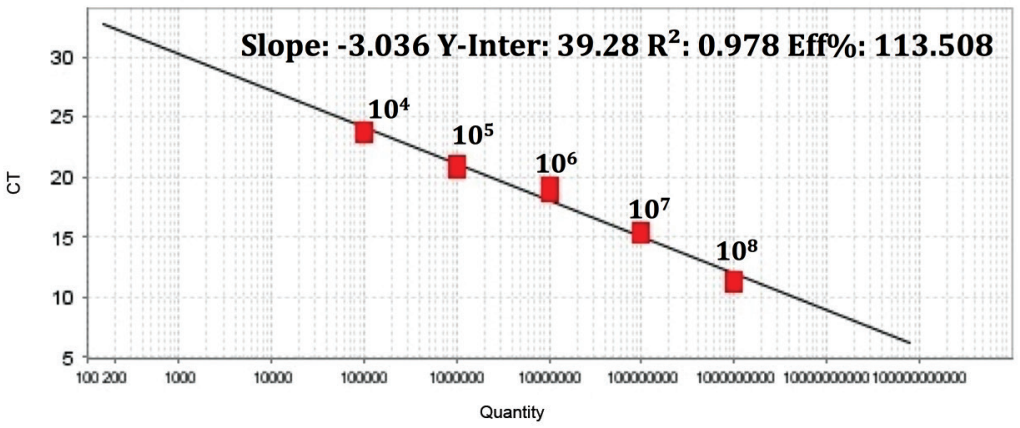

B

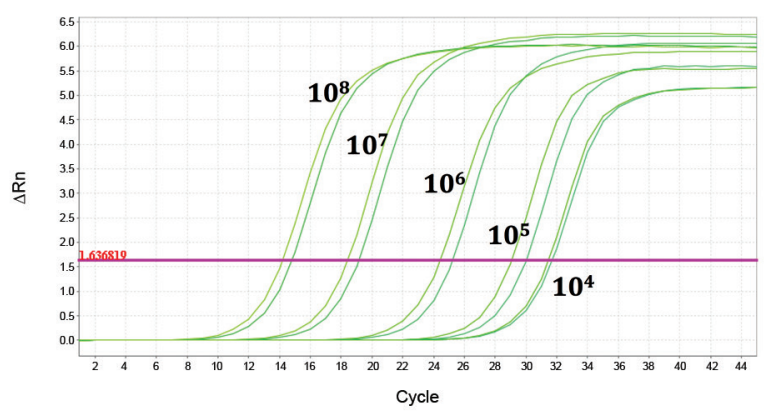

c

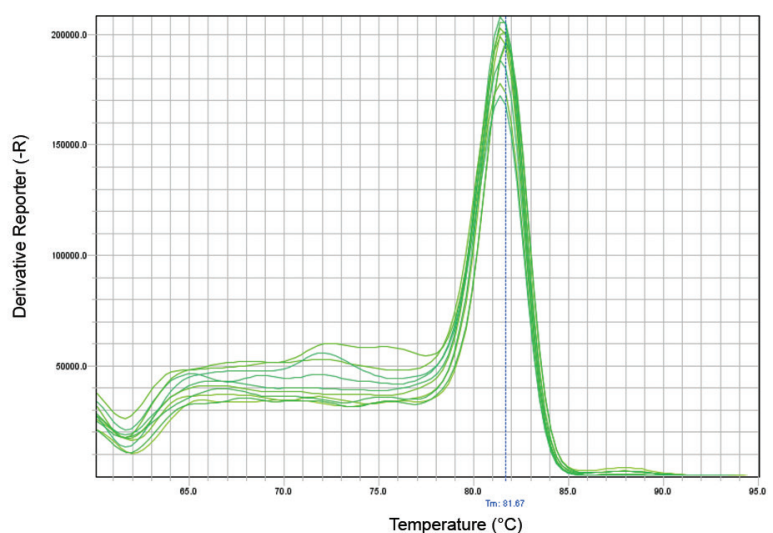

Fig. 2: melting peaks and amplification curve of real-time reverse transcriptase polymerase chain reaction (RT-PCR) for Vesiculovirus. (A) Melting peaks of real-time RT-PCR obtained from Vesiculovirus described in Table I. (B) Amplification curve obtained for the Vesiculovirus described in Table I.

The serosurveys studies performed in several places of Brazil have shown neutralising antibodies to PIRYV in more than $10 \%$ of the participants. Based on an accidental infection in the laboratory, we know that PIRYV produces an acute febrile illness (Pinheiro et al. 1974, Figueiredo et al. 1985, Tavares-Neto et al. 1990, Souza et al., in press). In contrast, we have tested 410 sera of patients with acute febrile illness by the real-time RTPCR for VSV, but all samples were negative for VSV. It is possible that most human infections by VSV in nature are asymptomatic, oligosymptomatic or produce a short period of viraemia. In addition, currently, little is known about mechanisms of maintenance and transmission of VSV in nature. Here, we have analysed ticks and mosquitoes from different places of Brazil, but all samples were negative to VSV. A novel, rapid, sensitive, VSV genus-specific, and reproducible SYBR Green real time RT-PCR was developed for detection and quantification of Vesiculovirus. This reaction was sensitive with a detection limit of 10 RNA copies $/ \mathrm{mL}$ and proved to be able to diagnose and quantify VSV Alagoas in serum samples from cattle and equines.

\section{ACKNOWLEDGEMENTS}

To Roberta D‘Angelo Azevedo and Sarah Cristina Andrade Silva of Laboratory of Entomology and Venomous Animals, Zoonosis Control Center, Ribeirão Preto City Hall, São
Paulo, Brazil, for supply and identification of tick samples, Prof Dr Eduardo Flores and Juliana Cargnelutti, from Federal University of Santa Maria, Rio Grande do Sul, Brazil.

\section{REFERENCES}

Afshar A, Dulac GC, Wright PF, Martin D. Application of indirect ELISA for detection of bovine antibodies against vesicular stomatitis viruses. J Vet Diagn Invest. 1993; 5(1): 26-32.

Bonutti DW, Figueiredo LT. Diagnosis of Brazilian vesiculoviruses by reverse transcription-polymerase chain reaction. Mem Inst Oswaldo Cruz. 2005; 100(2): 193-6.

Bronzoni RVM, Baleotti FG, Nogueira RMR, Nunes M, Figueiredo LTM. Duplex reverse transcription-PCR followed by nested PCR assays for detection and identification of Brazilian alphaviruses and flaviviruses. J Clin Microbiol. 2005; 43(2): 696-702.

Cargnelutti JF, Olinda RG, Maia LA, de Aguiar GM, Neto EG, Simoes SV, et al. Outbreaks of Vesicular stomatitis Alagoas virus in horses and cattle in northeastern Brazil. J Vet Diagn Invest. 2014; 26(6): 788-94.

Fernández J, Agüero M, Romero L, Sánchez C, Belák S, Arias M, et al. Rapid and differential diagnosis of foot-and-mouth disease, swine vesicular disease, and vesicular stomatitis by a new multiplex RT-PCR assay. J Virol Methods. 2008; 147(2): 301-11.

Figueiredo LT, da Rosa AP, Fiorillo AM. Prevalence of neutralizing antibodies to Piry arbovirus in subjects of the region of Ribeirão Preto, state of São Paulo. Rev Inst Med Trop Sao Paulo. 1985; 27(3): 157-61.

Figueiredo LTM. Piry virus. In: D Liu. Molecular detection of human viral pathogens. Boca Raton: CRC Press; 2011. p. 419-24. 
Hole K, Clavijo A, Pineda LA. Detection and serotype-specific differentiation of vesicular stomatitis virus using a multiplex, realtime, reverse transcription-polymerase chain reaction assay. $\mathrm{J}$ Vet Diagn Invest. 2006; 18(2): 139-46.

Katoh K, Standley DM. MAFFT multiple sequence alignment software version 7: improvements in performance and usability. Mol Biol Evol. 2013; 30(4): 772-80.

Kumar S, Jadi RS, Anakkathil SB, Tandale BV, Mishra AC, Arankalle VA. Development and evaluation of a real-time one step reverse-transcriptase PCR for quantitation of Chandipura virus. BMC Infect Dis. 2008; 8: 168.

Lichty BD, Power AT, Stojdl DF, Bell JC. Vesicular stomatitis virus: re-inventing the bullet. Trends Mol Med. 2004; 10(5): 210-6.

Mackay IM. Real-time PCR in the microbiology laboratory. Clin Microbiol Infect. 2004; 10(3): 190-212.

Mead DG, Ramberg FB, Besselsen DG, Mare CJ. Transmission of vesicular stomatitis virus from infected to noninfected black flies cofeeding on nonviremic deer mice. Science. 2000; 287(5452): 485-7.

Menghani S, Chikhale R, Raval A, Wadibhasme P, Khedekar P. Chandipura virus: an emerging tropical pathogen. Acta Trop. 2012; 124(1): $1-14$

Papin JF, Vahrson W, Dittmer DP. SYBR green-based real-time quantitative PCR assay for detection of West Nile Virus circumvents false-negative results due to strain variability. J Clin Microbiol. 2004; 42(4): 1511-8

Pauszek SJ, Barrera JC, Goldberg T, Allende R, Rodríguez LL. Genetic and antigenic relationships of vesicular stomatitis viruses from South America. Arch Virol. 2011; 156(11): 1961-8.

Pinheiro FP, Bensabath G, Andrade AH, Lins ZC, Fraiha H, Tang AT, et al. Infectious diseases along Brazil's trans-amazon high- way: surveillance and research. Bull Pan Am Health Organ. 1974; 8(2): 111-22.

Rajasekharan S, Rana J, Gulati S, Gupta V, Gupta S. Neuroinvasion by Chandipura virus. Acta Trop. 2014; 135: 122-6.

Rodriguez LL, Letchworth GJ, Spiropoulou CF, Nichol ST. Rapid detection of vesicular stomatitis virus New Jersey serotype in clinical samples by using polymerase chain reaction. J Clin Microbiol. 1993; 31(8): 2016-20.

Rodriguez LL. Emergence and re-emergence of vesicular stomatitis in the United States. Virus Res. 2002; 85(2): 211-9.

Schmitt B. Vesicular stomatitis. Vet Clin North Am Food Anim Pract. 2002; 18: 453-9.

Smith PF, Howerth EW, Carter D, Gray EW, Noblet R, Mead DG. Mechanical transmission of vesicular stomatitis New Jersey virus by Simulium vittatum (Diptera: Simuliidae) to domestic swine (Sus scrofa). J Med Entomol. 2009; 46(6): 1537-40.

Tavares-Neto J, Travassos da Rosa AP, Ataide M, Morais-Souza H, Vasconcelos P, Travassos da Rosa J. Frequency of neutralizing antibodies to the vesiculovirus Piry, in blood donors of Uberaba, Minas Gerais, Brazil. Rev Inst Med Trop Sao Paulo. 1990; 32(3): 211-4.

Tesh R, Saidi S, Javadian E, Loh P, Nadim A. Isfahan virus, a new vesiculovirus infecting humans, gerbils, and sandflies in Iran. Am J Trop Med Hyg. 1977; 26(2): 299-306.

Travassos da Rosa AP, Tesh RB, Travassos da Rosa JF, Herve JP, Main Jr AJ. Carajas and Maraba viruses, two new vesiculoviruses isolated from phlebotomine sand flies in Brazil. Am J Trop Med Hyg. 1984; 33(5): 999-1006.

Wilson WC, Letchworth GJ, Jimenez C, Herrero MV, Navarro R, Paz $\mathrm{P}$, et al. Field evaluation of a multiplex real-time reverse transcription polymerase chain reaction assay for detection of Vesicular stomatitis virus. J Vet Diagn Invest. 2009; 21(2): 179-86. 